\title{
Cross-sectional study of cytomegalovirus shedding and immunological markers among seropositive children and their mothers
}

Jennifer D Stowell ${ }^{1}$, Karen Mask', Minal Amin², Rebekah Clark ${ }^{3}$ Denise Levis ${ }^{1}$, Will Hendley ${ }^{2}$, Tatiana M Lanzieri ${ }^{2}$, Sheila C Dollard ${ }^{2}$ and Michael J Cannon ${ }^{1 *}$

\begin{abstract}
Background: Congenital cytomegalovirus (CMV) is the leading infectious cause of birth defects in the United States. To better understand factors that may influence CMV transmission risk, we compared viral and immunological factors in healthy children and their mothers.

Methods: We screened for CMV IgG antibodies in a convenience sample of 161 children aged 0-47 months from the Atlanta, Georgia metropolitan area, along with 32 mothers of children who screened CMV-seropositive. We assessed CMV shedding via PCR using saliva collected with oral swabs (children and mothers) and urine collected from diapers using filter paper inserts (children only).

Results: CMV IgG was present in 31\% (50/161) of the children. Half (25/50) of seropositive children were shedding in at least one fluid. The proportion of seropositive children who shed in saliva was 100\% (8/8) among the 4-12 month-olds, 64\% (9/14) among 13-24 month-olds, and 40\% (6/15) among 25-47 month-olds (P for trend = 0.003). Seropositive mothers had a lower proportion of saliva shedding $(21 \%[6 / 29])$ than children $(P<0.001)$. Among children who were shedding CMV, viral loads in saliva were significantly higher in younger children $(P<0.001)$; on average, the saliva viral load of infants (i.e., $<12$ months) was approximately 300 times that of two year-olds (i.e., 24-35 months). Median CMV viral loads were similar in children's saliva and urine but were $10-50$ times higher $(P<0.001)$ than the median viral load of the mothers' saliva. However, very high viral loads (> one million copies $/ \mathrm{mL}$ ) were only found in children's saliva (31\% of those shedding); children's urine and mothers' saliva specimens all had fewer than 100,000 copies/mL. Low lgG avidity, a marker of primary infection, was associated with younger age $(p=0.03)$, higher viral loads in saliva $(p=0.02)$, and lower antibody titers $(p=0.005)$.
\end{abstract}

Conclusions: Young CMV seropositive children, especially those less than one year-old may present high-risk CMV exposures to pregnant women, especially via saliva, though further research is needed to see if this finding can be generalized across racial or other demographic strata.

Keywords: Congenital, Cytomegalovirus, Transmission, Pregnancy, Children

\section{Background}

Congenital cytomegalovirus (CMV) is a leading viral cause of childhood disability that remains underemphasized due to challenges in diagnosis, prevention, and treatment [1-5]. Many people are infected with CMV, yet most of these infections are asymptomatic and therefore unlikely

\footnotetext{
* Correspondence: mcannon@cdc.gov

'National Center on Birth Defects and Developmental Disabilities, Centers for Disease Control and Prevention, 1600 Clifton Rd NE, MS E-86, Atlanta, GA 30333, USA

Full list of author information is available at the end of the article
}

to be diagnosed [6]. Thus, a pregnant woman may have or acquire CMV infection and be unaware that she is infected and at risk of passing the infection to her fetus [7-10]. Furthermore, because most women are unaware of CMV, and many pregnancies are unplanned $(37 \%$ in the United States [11]), opportunities for preventing congenital CMV through behavioral change are often missed [1,12-14].

Reducing risk for pregnant women requires a sound understanding of CMV transmission routes and sources. 
CMV transmission appears to require direct contact with infected body fluids. Seroconversion data point to young children as an important source of infection for pregnant women. In a comprehensive literature review, annual seroconversion rates were much higher among child care workers (8.5\%) and parents with a child known to be shedding CMV (24\%) than among the general population of pregnant women, healthcare workers, or parents with a child known not to be shedding CMV (all with annual seroconversion rates of $\sim 2 \%$ ) [15]. CMV infection can also result from intimate contact between adults $[16,17]$.

A better understanding of the relative importance of children versus adults as sources of CMV infection might lead to improved prevention messages for pregnant women. Their risk of CMV infection is influenced by the different ways in which they interact with children and adults, but other factors may also be important. Although young children are more prone to transfer body fluids to others and into their surrounding environment, adults also exchange body fluids with one another, perhaps less indiscriminately, but with some frequency nonetheless. Thus, it seems likely that infection risk may also be influenced by viral or immunological factors, or by recency of infection in the source (i.e., primary vs. non-primary infection). Although some of these factors, such as prevalence of IgG antibody positivity or viral shedding, have been explored thoroughly in children and adults, other factors, such as IgG titers, IgG avidity, viral loads, recency of infection, or specimen type (e.g., saliva vs. urine), remain understudied. In addition, most studies of these other factors [18-32] have not compared children and adults or have been done in congenitally infected children rather than in postnatally infected healthy children-the latter being a more important infection source because they greatly outnumber children with congenital infection.

To better understand factors that may influence CMV transmission risk for pregnant women, we carried out a descriptive epidemiology study of viral and immunological factors in healthy children and compared them to factors in adults (i.e., their mothers). In this way we hoped to inform possible behavioral measures for preventing maternal CMV infection or reinfection during pregnancy.

\section{Methods}

\section{Study population}

Over the course of approximately six months we enrolled a convenience sample of children without chronic medical conditions aged 0-47 months from the Atlanta, GA metropolitan area for participation in this cross-sectional study. None of the children had a diagnosis of congenital CMV infection. Aside from age, the only other inclusion requirement was that the child be using diapers. We used a variety of recruitment methods including posted flyers, e-mail list announcements, word-of-mouth, and on-site recruitment in outpatient pediatric clinics. Subsequently, we enrolled the mothers $(\mathrm{N}=32)$ of those children who tested CMV-seropositive and were selected for longitudinal follow-up (Cannon et al., companion paper). The study was approved by the Institutional Review Board (IRB) at the U.S. Centers for Disease Control and Prevention (CDC). Informed consent for each participant, signed by the mother, was obtained during the enrollment process.

We administered a survey at the time of enrollment to capture demographic and socioeconomic data such as sex, age, race/ethnicity, day care attendance, household income, insurance status, and mother's educational attainment and knowledge of CMV.

\section{Specimen collection \& testing}

Children were tested for CMV IgG antibody in serum (i.e., CMV seropositivity) and CMV DNA in saliva and urine (CMV shedding). Seropositive children were enrolled in a 12-week longitudinal follow-up study described elsewhere (Cannon et al., companion paper). The mothers of CMVseropositive children were typically enrolled 2-4 weeks after their child's visit, and were tested for CMV IgG antibody in serum and CMV DNA in saliva.

Blood specimens for antibody testing were taken via finger stick (from mothers and older children) or heel stick (from younger children). Blood was collected on a dried blood spot (DBS) card which was allowed to dry. DBS cards were delivered at room temperature to the laboratory within 24 hours of collection and were stored at $-20^{\circ} \mathrm{C}$ pending laboratory testing. Serum was eluted from the DBS as described [33] and tested using a standard CMV ELISA assay (Sera Quest ${ }^{\circ}$, Doral, Florida).

CMV IgG titration was done on blood specimens (when enough remained) by performing two-fold dilutions and testing by ELISA. Sufficient specimen remained to obtain antibody titer results for 36 of 50 seropositive children and 28 of 29 seropositive mothers.

CMV IgG avidity testing was performed on blood (when enough remained) using standard Euroimmune ${ }^{\bullet}$ ELISA kits (Luebeck, Germany) to identify recent infection. Sufficient specimen remained to obtain antibody avidity results for 40 of 50 seropositive children and 29 of 29 seropositive mothers.

Saliva specimens from children were collected using sterile oral swabs. Each swab was placed in the child's mouth for at least 20 seconds to ensure adequate absorption of saliva, and was then inserted into a collection tube. Mothers' saliva was collected by having study subjects expectorate directly into sterile tubes. All specimens were kept refrigerated during transport to the laboratory within 24 hours, where they were stored at $-80^{\circ} \mathrm{C}$ pending laboratory testing.

Viral DNA was extracted from each swab through a quick extract method to detect CMV DNA in saliva. 
After thawing, $300 \mu \mathrm{l}$ of lysis/elution buffer were added to each collection tube, which was then incubated and mixed at $56^{\circ} \mathrm{C}$ for one hour and then at $100^{\circ} \mathrm{C}$ for two minutes with agitation. The tube was then rapidly cooled on ice for 5-10 minutes, after which it was centrifuged for 1-2 minutes. The swab was removed and the specimen was tested by CMV real-time PCR, targeting the glycoprotein $B$ gene [23].

Children's urine was collected using a diaper insert. Whatman 903 filter paper $\left(1^{\prime \prime} \times 4^{\prime \prime}\right)$ was inserted into the inner panel of the diaper prior to placement on the child. After urination, the insert was removed from the diaper and allowed to air dry. The insert was transported to the laboratory within 24 hours where it was stored at $-80^{\circ} \mathrm{C}$ pending laboratory testing.

Viral DNA was extracted from the filter paper via the thermal shock method [34] to detect CMV DNA in urine, with modifications as described by Kharrazi et al. [33]. Taqman-based PCR was then performed that targeted the CMV glycoprotein B gene [23].

The limits of PCR detection were estimated to be 1,600 copies/mL for saliva and 16,000 copies/mL for urine. These limits are considerably higher than our detection limit for sterile specimens (e.g., blood) collected in clinical settings, which is 70 copies $/ \mathrm{mL}$. Two factors led to these higher limits of detection: 1) To avoid falsepositives, the PCR assay cutoff was raised five-fold from one copy per reaction (70 copies $/ \mathrm{ml}$ ) to five copies per reaction (350 copies $/ \mathrm{ml}$ ) because saliva is not sterile and urine was collected in an unsterile manner, and unsterile specimens are more susceptible to trace amounts of contamination from the environment; 2) The methods of specimen collection (i.e., swabs and filter paper) were necessary to enable in-home collection by mothers, but they resulted in reduced sample volume which raised the limit of detection approximately five-fold for saliva in swabs and 50-fold for urine in filter paper.

Notably, urine dried on filter paper was usually colorless. To confirm the presence of urine we tested for urea, following the manufacturer's instructions (Bioassay Systems ${ }^{\circ}$, Hayward, CA), in a sample immediately adjacent to the sample used for PCR. During recruitment, we were unable to collect a urine specimen from seven of the children, and an additional three urine specimens did not have detectable urea on the filter paper and were thus excluded from analysis. Consequently, urine results were available for only 151 children.

\section{Statistical analysis}

Statistical analyses were done using SAS version 9.3 (Cary, NC). We calculated P-values for proportions by using the Chi-Square or Fisher's exact tests, as appropriate. When comparing viral loads or antibody titers, we used the Wilcoxon Rank-Sum test. To evaluate associations with age, we performed linear regressions on $\log _{10}$ transformed viral loads and on $\log _{\mathrm{e}}$ transformed antibody titers.

\section{Results}

We screened 161 children during the study (Table 1). The children were different from the general population of U.S. children in important ways, including that their

Table 1 Characteristics of children and mothers

\begin{tabular}{|c|c|c|}
\hline Variable & Result & $\begin{array}{l}\text { Comparable } \\
\text { U.S. averages }\end{array}$ \\
\hline Sex of child & & $\begin{array}{l}\text { (US population <5yrs } \\
\text { in 2010) [35] }\end{array}$ \\
\hline Female & $45 \%(72 / 161)$ & $48.9 \%$ \\
\hline Male & $55 \%(89 / 161)$ & $51.1 \%$ \\
\hline \multicolumn{3}{|l|}{ Age of children } \\
\hline $0-12$ months & $37 \%(60 / 161)$ & NA \\
\hline 13-24 months & $35 \%(57 / 161)$ & NA \\
\hline 25-47 months & $27 \%(44 / 161)$ & NA \\
\hline Maternal age & $\begin{array}{l}\text { Median }=34 \text { years } \\
\text { (range }=21-46)\end{array}$ & NA \\
\hline Race $^{*}$ & & {$[36]$} \\
\hline Non-Hispanic White & $69 \%(111 / 160)$ & $79.6 \%$ \\
\hline Asian/Asian American & $18 \%(29 / 160)$ & $4.6 \%$ \\
\hline Black/African American & $8 \%(13 / 160)$ & $12.9 \%$ \\
\hline Other & $4 \%(7 / 160)$ & $2.9 \%$ \\
\hline Ethnicity & & {$[36]$} \\
\hline Hispanic & $4 \%(7 / 161)$ & $15.8 \%$ \\
\hline Not Hispanic & $96 \%(154 / 161)$ & $84.2 \%$ \\
\hline $\begin{array}{l}\text { Maternal educational } \\
\text { attainment }\end{array}$ & & {$[37]$} \\
\hline Professional degree & $18 \%(29 / 161)$ & $10.2 \%$ \\
\hline Master's degree & $22 \%(36 / 161)$ & \\
\hline Bachelor's degree & $35 \%(57 / 161)$ & $19.4 \%$ \\
\hline Some college & $20 \%(32 / 161)$ & $\begin{array}{l}27.3 \% \text { (includes } \\
\text { associate degrees) }\end{array}$ \\
\hline High school/GED & $1 \%(2 / 161)$ & $30.7 \%$ \\
\hline Less than high school & $3 \%(5 / 161)$ & $12.4 \%$ \\
\hline Median household income & $\$ 75,000-\$ 100,000$ & $\$ 49,777[38]$ \\
\hline Insurance coverage & & {$[39]$} \\
\hline Employer & $76 \%(123 / 161)$ & $55.8 \%$ \\
\hline Self-insured & $6 \%(10 / 161)$ & $8.2 \%$ \\
\hline Public & $4 \%(6 / 161)$ & $\begin{array}{l}15.7 \% \text { (Medicaid } \\
\text { stats only) }\end{array}$ \\
\hline Don't know/not covered & $14 \%(22 / 161)$ & $16.7 \%$ (uninsured) \\
\hline Child ever attended day care & $39 \%(63 / 161)$ & $\begin{array}{l}32.9 \% \text { (non-relative } \\
\text { care) }[40]\end{array}$ \\
\hline CMV seropositive- children & $31 \%(50 / 161)$ & $37.5 \%[41]$ \\
\hline CMV seropositive - mothers & $91 \%(29 / 32)$ & $56.7 \%[41]$ \\
\hline
\end{tabular}

*Data missing for one child. 
parents had above average educational attainment and household income and were more likely to have health insurance through their employers. Nearly one third (31\%) of the children were CMV-seropositive (Table 1, Figure 1). Of these, half were shedding CMV in saliva and/or urine (Figure 1). Of the 111 seronegative children, three were shedding CMV in saliva or urine (Figure 1). We also screened 32 mothers of CMV-seropositive children, of whom 29 (91\%) were CMV-seropositive (Table 1). The age range of their children was similar to the age range of all the children in the study (data not shown).

CMV seroprevalence was higher among older children, with the exception that $0-3$ month-olds had an elevated seroprevalence (Figure 2), presumably the result of some having antibodies transferred passively from their mothers. Among the 13 seropositive children aged 0-3 months, only five had evidence of infection-either viral shedding or low avidity antibodies. Among seropositive children aged 4-12 months, all were shedding CMV and therefore were likely to have had their own infection, rather than maternal antibodies only.

Among children, prevalence of shedding did not change significantly with age in either saliva ( $P$ for trend $=0.70$ ) or urine ( $\mathrm{P}$ for trend $=0.63$ ). However, the proportion of seropositive children who shed in saliva decreased (Figure 2) from 100\% (8/8) among the 4-12 montholds, to $64 \%(9 / 14)$ among $13-24$ month-olds, to $40 \%$ $(6 / 15)$ among $25-47$ month-olds (P for trend $=0.003)$.
Seropositive mothers had an even lower proportion of saliva shedding (21\% [6/29]). Of the three seronegative mothers, two had children who were shedding in saliva and/or urine, and therefore would have elevated risk of acquiring CMV from their children. None of the three seronegative mothers seroconverted during the 12-week longitudinal follow-up study (Cannon et al., companion paper).

Although shedding prevalence was higher (Figure 1) in children's saliva $(16 \%[26 / 161])$ than in urine $(8 \%$ [12/ $151]$ ), a direct comparison is inappropriate because the limit of PCR detection for saliva $(1,600$ copies $/ \mathrm{mL})$ was lower than for urine $(16,000$ copies $/ \mathrm{mL})$. When using the less sensitive limit for both fluids (i.e., 16,000 copies/mL), the difference between shedding prevalences (Figure 3) was small ( $11 \%$ vs. $8 \%, \mathrm{P}=0.34)$.

Among children who were shedding CMV, viral loads were significantly lower (Figure 3 ) at older ages for saliva ( $\mathrm{P}<0.001)$ but not for urine $(\mathrm{P}=0.22)$. On average, the saliva viral load of infants (i.e., $<12$ months) was approximately 300 times that of 2 year-olds (i.e., 24-35 months) (Figure 3). Median CMV viral loads were similar in children's saliva and urine (Figure 4A, Table 2), but were $10-50$ times higher $(\mathrm{P}<0.001)$ than the median viral load of the mothers' saliva (Figure 4A, Table 2). Of note, viral loads at the high end of the distributions were even more disparate-for example, more than $25 \%$ of the children's saliva viral loads were greater than

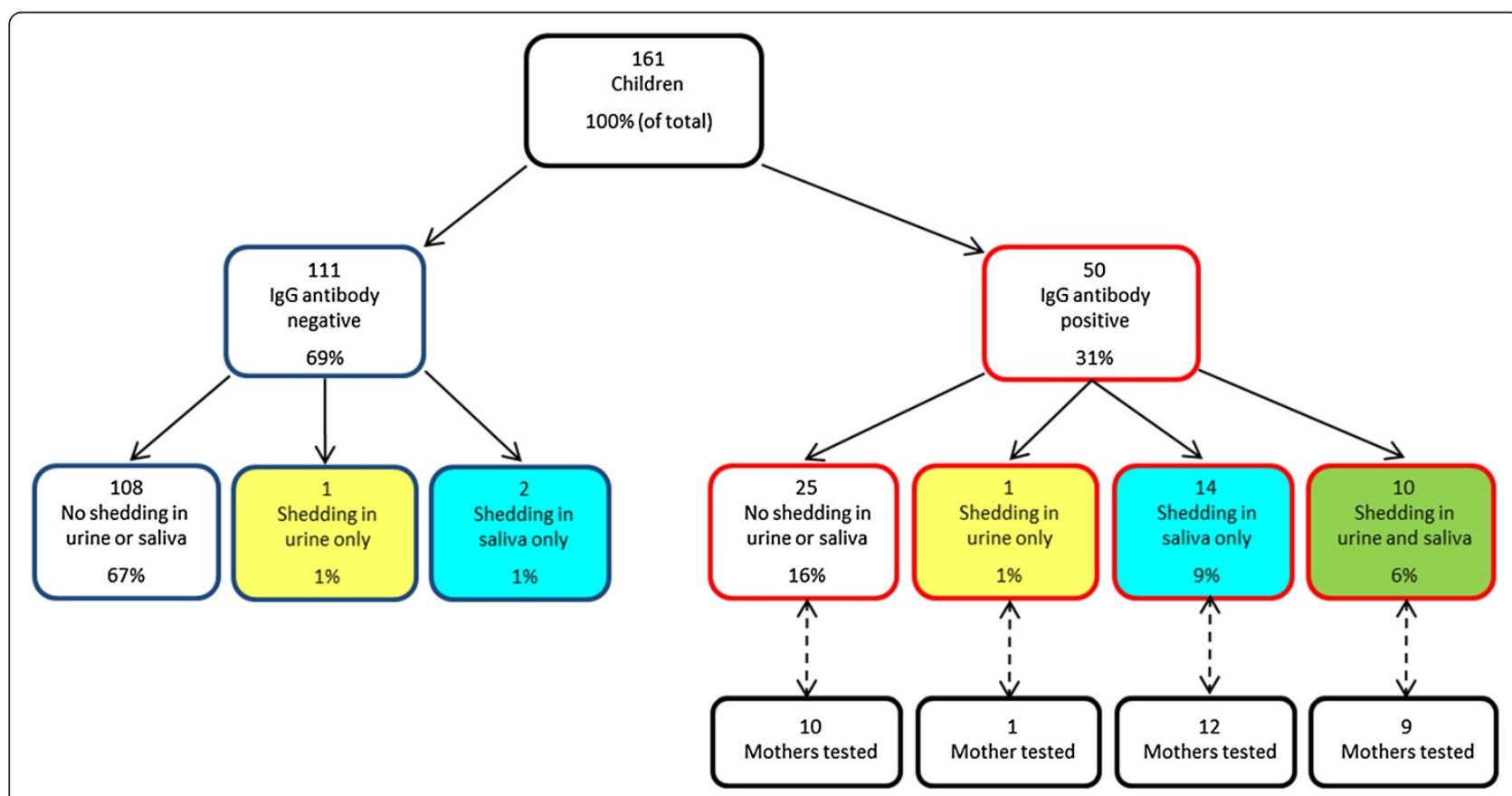

Figure 1 Number, antibody status, and CMV shedding status of children enrolled in the study. Red outlines represent children with CMV IgG antibody and blue outlines represent children without CMV IgG antibody. Yellow shading represents children shedding CMV in urine only, blue shading represents children shedding in saliva only, and green shading represents children shedding in both urine and saliva. CMV testing was also done in a subset of mothers of children who were CMV antibody positive. 


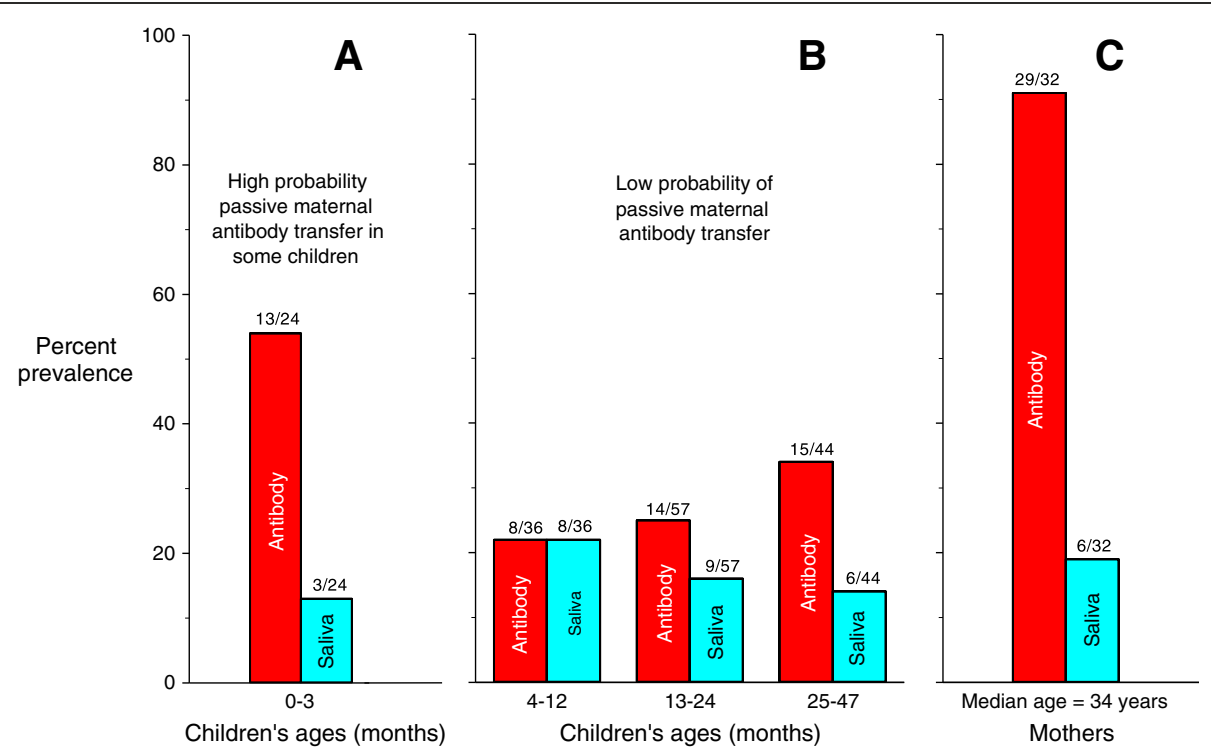

Figure 2 Prevalences of CMV IgG antibody and CMV shedding in saliva among children as a function of age in months. Prevalences of CMV IgG antibody and CMV shedding in saliva are also shown for the mothers who were screened. Red shading represents antibody results and blue shading represents saliva results. Panel A shows data from children ages 0-3 months; Panel B shows data from children ages 4-47 months; Panel $\mathbf{C}$ shows data from mothers. Antibody prevalences of mothers and children are not directly comparable because the children came from an unselected population whereas the mothers were selected for testing only if their children were CMV-seropositive, and therefore the seroprevalence among mothers was higher than would be expected in a general population.

one million copies/mL, while all of the children's urine viral loads and mothers' saliva viral loads were less than 100,000 copies/mL (Figure 4A). Among children shedders, low antibody avidity was associated with higher viral loads in saliva (Figure 4B, Table 2), but day care attendance was not associated with higher viral loads in saliva or urine (Figure 4C, Table 2).

Mothers' antibody titers were higher than those of children (Table 2, Figure 5B), and among children anti- body titers increased with age (Figure 5A). Children $0-12$ months were more likely to have low avidity antibodies $(36 \%, 6 / 17)$ than were older children $(4 \%[1 / 23])$ $(P=0.03)$. Antibody titers were not associated with shedding in one or more specimen types (Figure 6A, all pairwise $P$ values $>0.20$ ), but were associated with high or intermediate antibody avidity (Figure 6B, Table 2, $\mathrm{P}=0.005)$. All three mothers with low antibody avidity (i.e., suggesting recent infection) had children who had

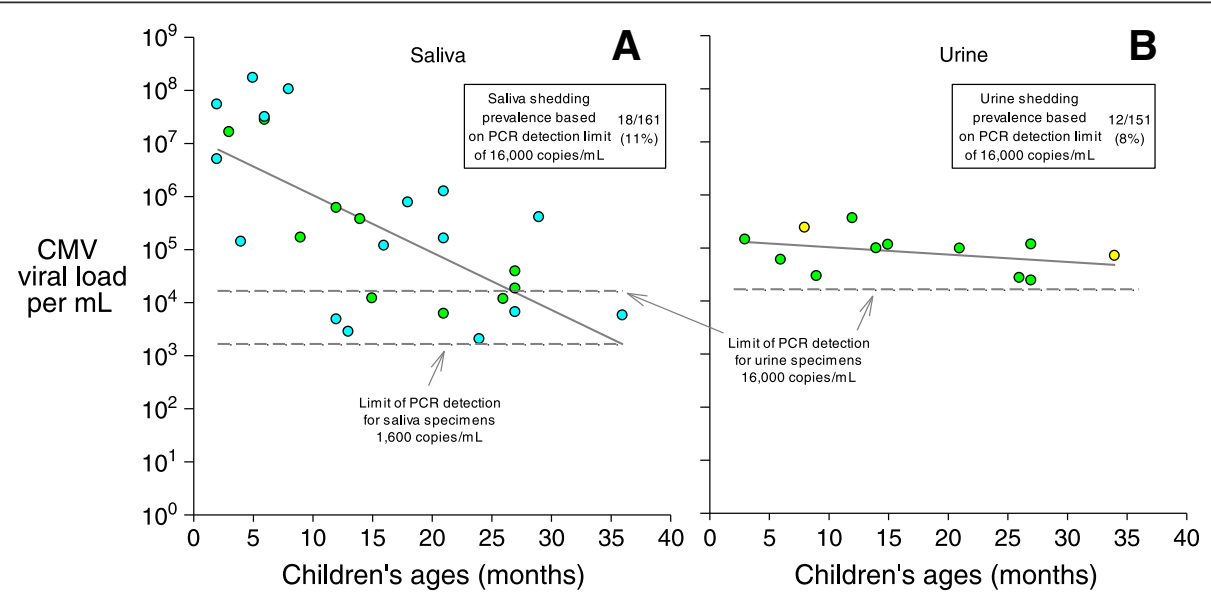

Figure 3 CMV viral loads per $\mathrm{mL}$ as a function of children's ages in months. Panel A shows results for saliva viral loads and panel B shows results for urine viral loads. Circles are only plotted for children who were shedding; negative results (i.e., viral loads below the limit of detection) are not plotted. Yellow circles represent children shedding CMV in urine only, blue circles represent children shedding in saliva only, and green circles represent children shedding in both urine and saliva. The regression line in Panel $\mathbf{A}$ is $\log _{10}$ (CMV viral load) $=7.1-0.108$ (age in months), with $r^{2}=0.46$ and $P<0.001$; the regression line in Panel $\mathbf{B}$ is $\log _{10}\left(C M V\right.$ viral load) $=5.2-0.014$ (age in months), with $r^{2}=0.14$ and $P=0.22$. 


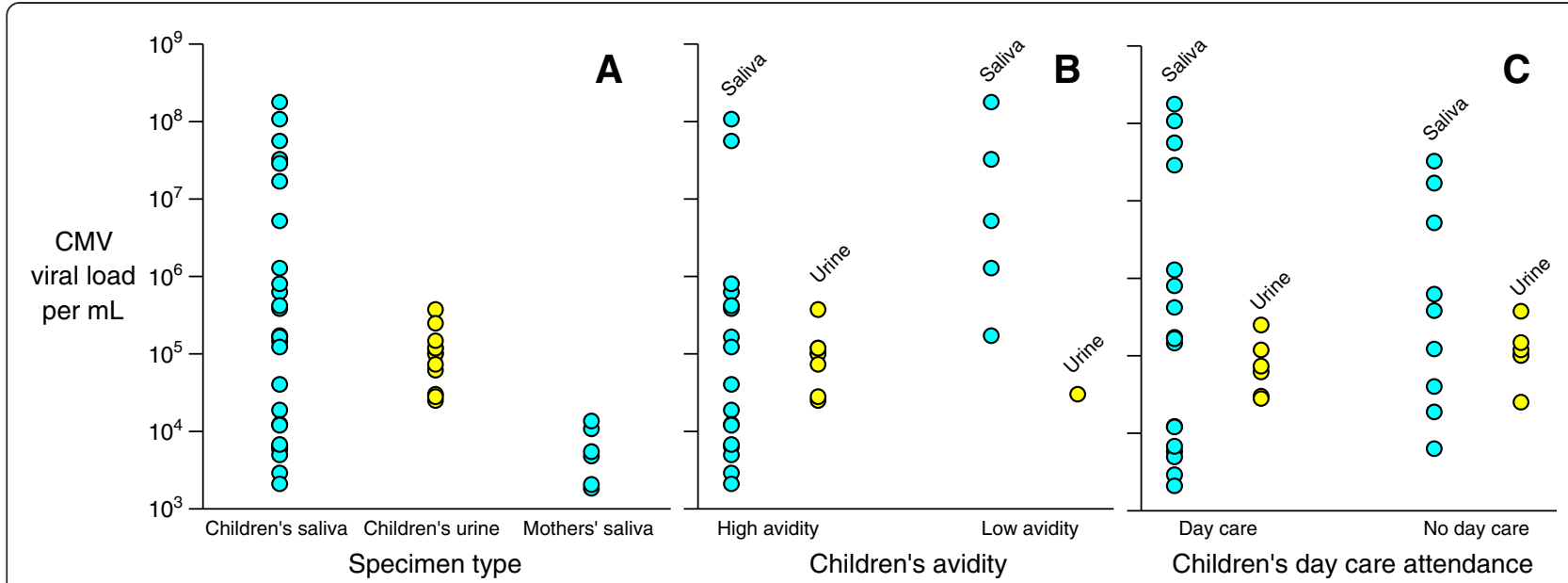

Figure $4 \mathrm{CMV}$ viral loads per $\mathrm{mL}$ stratified by three different variables. Panel $\mathbf{A}$ shows viral loads stratified by specimen type (saliva vs. urine) and source (child vs. mother). Panel B shows viral loads for children only stratified by whether the child had high or intermediate versus low CMV IgG antibody avidity. Panel C shows viral loads stratified by day care attendance. Circles are only plotted for children who were shedding; negative results (i.e., viral loads below the limit of detection) are not plotted. Blue circles represent saliva results and yellow circles represent urine results.

high viral loads in saliva ( $>750,000$ copies $/ \mathrm{mL})$, but only one of these mothers was shedding herself.

Day care attendance was associated with a three-fold higher prevalence of viral shedding (Table 2, $\mathrm{P}<0.001$ ) and with an $11 \%$ higher seroprevalence ( $38 \%$ vs. $27 \%$ ), though the latter association did not achieve conventional levels of statistical significance (Table $2, \mathrm{P}=0.06$ ). In contrast, day care attendance was not a predictor of high CMV viral loads in saliva or urine, low avidity antibodies, or high antibody titers (Table 2).

\section{Discussion}

Our study of the descriptive epidemiology of CMV infection among children and mothers produced several new findings that have implications for prevention of CMV infection among women of reproductive age: 1) more than half of CMV-seropositive healthy young children shed CMV DNA in saliva and/or urine, a much higher shedding rate than that of seropositive healthy adults; 2) among seropositive children, the prevalence of shedding and the magnitude of CMV viral loads tended to be greater among younger children; 3) CMV viral loads were typically higher in children's saliva and urine than in mothers' saliva; 4) the highest viral loads (> one million copies $/ \mathrm{mL}$ ) were only found in children's saliva; 5) low CMV IgG avidity was associated with younger age, CMV shedding, and low CMV IgG titers; and 6) high CMV IgG titers were associated with older age. We will discuss each of these new findings and their implications in turn.

Although adults have higher CMV seroprevalence than children [41], we found that seropositive children are much more likely to shed CMV. In our study, more than half of the CMV-seropositive children were shedding compared to one-fifth of the CMV-seropositive mothers. Furthermore, after excluding the children aged $0-3$ months, presumably all of whom were likely to have had passively acquired maternal antibodies, we found that younger seropositive children were more likely to shed CMV than older seropositive children. The higher proportion of shedding in seropositive children, especially younger children, may help explain why they are an important source of CMV infection [15]. It also suggests that adults may have better immune control of CMV, that duration of shedding is longer for primary infections (since the children are more likely to have had recent primary infections), or that children are more likely to be exposed to reinfections.

The finding of a high proportion of shedding among seropositive children is new; although dozens of studies have measured CMV shedding among children, we could only identify eight previous studies that measured both viral shedding and antibody among healthy children (i.e., children without congenital CMV) [20,22,42-47]. However, most of these studies either did not report the shedding proportion among the seropositives or did not look at both laboratory tests in the same children. Only one of these studies [47] reported an unbiased proportion of shedding among seropositive children-33\% (7/21) - but most of the children were older-in fact, only five seropositive children were under the age of five, which may, in light of our finding of less shedding among older children, have led to a lower shedding proportion in that study. Importantly, our prevalence of shedding in seropositive adults is likely to be an overestimate because, unlike the children in the study, the mothers were selected for testing because they already had a risk factor, i.e. a CMV seropositive child. 
Table 2 Associations between select demographic, viral, and immunological variables

\begin{tabular}{|c|c|c|c|c|c|c|c|c|c|c|c|c|c|c|}
\hline \multirow[t]{2}{*}{ Variable } & \multirow{2}{*}{$\begin{array}{l}\text { CMV shedding } \\
\text { in saliva and// } \\
\text { or urine }\end{array}$} & \multirow[t]{2}{*}{ P-value } & \multicolumn{2}{|c|}{ Saliva viral load } & \multirow[t]{2}{*}{ P-value ${ }^{a}$} & \multicolumn{2}{|c|}{ Urine viral load } & \multirow[t]{2}{*}{ P-value ${ }^{b}$} & \multirow{2}{*}{$\begin{array}{l}\text { lgG } \\
\text { antibody }\end{array}$} & \multirow[t]{2}{*}{ P-value } & \multirow{2}{*}{$\begin{array}{l}\text { Low IgG } \\
\text { avidity }\end{array}$} & \multirow[t]{2}{*}{ P-value } & \multirow{2}{*}{$\begin{array}{l}\text { IgG titers }{ }^{-1} \\
\text { (GMT) }^{c}\end{array}$} & \multirow[t]{2}{*}{ P-value } \\
\hline & & & Mean & Median & & Mean & Median & & & & & & & \\
\hline \multicolumn{15}{|l|}{ Group } \\
\hline Children & $17 \%(28 / 161)$ & & $1.6 \times 10^{7}$ & $1.6 \times 10^{5}$ & & $1.1 \times 10^{5}$ & $9.6 \times 10^{4}$ & $0.37^{d}$ & $31 \%(50 / 161)$ & & $18 \%(7 / 40)$ & & 224 & \\
\hline Mothers & $19 \%(6 / 32)$ & 0.83 & $6.1 \times 10^{3}$ & $4.9 \times 10^{3}$ & $<0.001$ & - & - & $<0.001^{\mathrm{e}}$ & $91 \%(29 / 32)$ & f & $10 \%(3 / 29)$ & 0.50 & 464 & 0.002 \\
\hline \multicolumn{15}{|l|}{ CMV IgG avidity (all) } \\
\hline Low & $60 \%(6 / 10)$ & & $1.6 \times 10^{6}$ & $2.5 \times 10^{6}$ & & - & - & & - & & - & & 136 & \\
\hline High or intermediate & $39 \%(23 / 59)$ & 0.30 & $4.4 \times 10^{4}$ & $1.2 \times 10^{4}$ & 0.02 & - & - & NA & - & NA & - & NA & 353 & 0.005 \\
\hline \multicolumn{15}{|l|}{$\begin{array}{l}\text { CMV shedders } \\
\text { (children only) }\end{array}$} \\
\hline No & - & & - & - & & - & - & & $19 \%(25 / 133)$ & & $12 \%(2 / 17)$ & & 321 & \\
\hline Yes & - & NA & - & - & NA & - & - & NA & $89 \%(25 / 28)$ & $<0.001$ & $23 \%(5 / 23)$ & 0.68 & 290 & 0.68 \\
\hline \multicolumn{15}{|l|}{$\begin{array}{l}\text { Day care attendance } \\
\text { (children only) }\end{array}$} \\
\hline Never & $9 \%(9 / 98)$ & & $5.9 \times 10^{6}$ & $3.7 \times 10^{5}$ & & $1.4 \times 10^{5}$ & $1.1 \times 10^{5}$ & & $27 \%(26 / 98)$ & & $21 \%(4 / 19)$ & & 192 & \\
\hline Ever & $30 \%(19 / 64)$ & $<0.001$ & $2.1 \times 10^{7}$ & $1.6 \times 10^{5}$ & 0.63 & $8.9 \times 10^{4}$ & $6.5 \times 10^{4}$ & 0.38 & $38 \%(24 / 63)$ & 0.06 & $14 \%(3 / 21)$ & 0.69 & 258 & 0.35 \\
\hline
\end{tabular}

${ }^{a}$ Wilcoxon Rank-Sum test comparing $\log _{10}$ viral loads in saliva.

${ }^{b}$ Wilcoxon Rank-Sum test comparing $\log _{10}$ viral loads in urine.

'Wilcoxon Rank-Sum test comparing geometric mean titers (GMT).

${ }^{\mathrm{d} C}$ Comparison is between children's saliva and urine.

eComparison is between children's urine and mothers' saliva.

${ }^{\mathrm{f}}$ Antibody prevalences between mothers and children were not directly comparable because the children came from an unselected population whereas the mothers were selected for testing only if their children were

CMV-seropositive, and therefore the seroprevalence among mothers was higher than would be expected in a general population.

Dashes are inserted where a comparison does not make sense or is redundant, or where data were insufficient.

P-values comparing proportions are chi-squared or Fisher's exact test as appropriate; p-values less than 0.05 are highlighted in bold font.

NA, not applicable. 


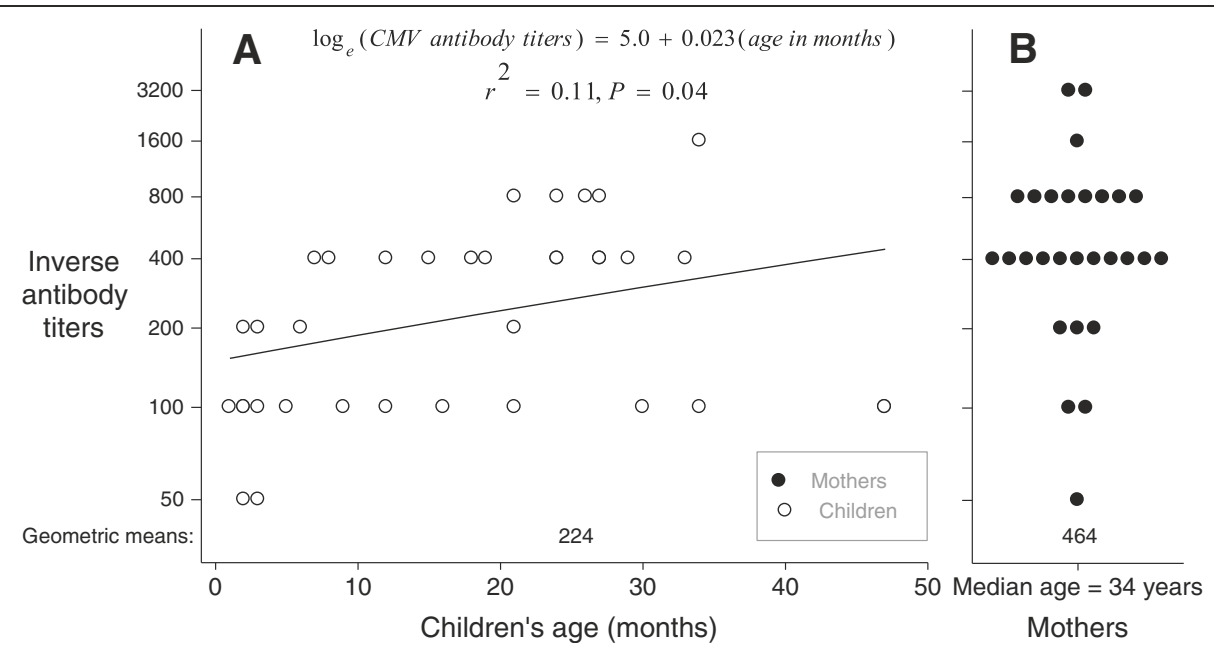

Figure 5 CMV IgG antibody titers among children and mothers. Panel A shows antibody titers as a function of age in months, including a regression line plotted to show the linear relationship between age in months and $\log _{e}$ viral loads. Panel $\mathbf{B}$ shows antibody titers among mothers, who had a median age of 34 years. Overall geometric mean antibody titers for children and for mothers are shown near the bottom of each panel. Circles are only plotted for individuals who had CMV IgG antibodies; negative results (i.e., antibody titers of zero) are not plotted. Black circles represent mothers' results and white circles represent children's results.

This may explain why our shedding proportion (21\%) was somewhat higher than that of previous studies of seropositive women, where the summary proportion of shedding in oral secretions was 13\% (74/556), though the difference was not statistically significant $[24,25,48-51]$.

In contrast to some previous findings, we found that CMV shedding in children was similar (using equivalent limits of PCR detection) for saliva (11\%) and urine (8\%). Previous studies that measured both urine and saliva shedding in healthy children found CMV more frequently in urine, with the prevalence difference ranging from $2 \%-20 \%$ [24]. However, one important difference between our study and these previous studies was that we measured shedding using PCR while the previous studies all

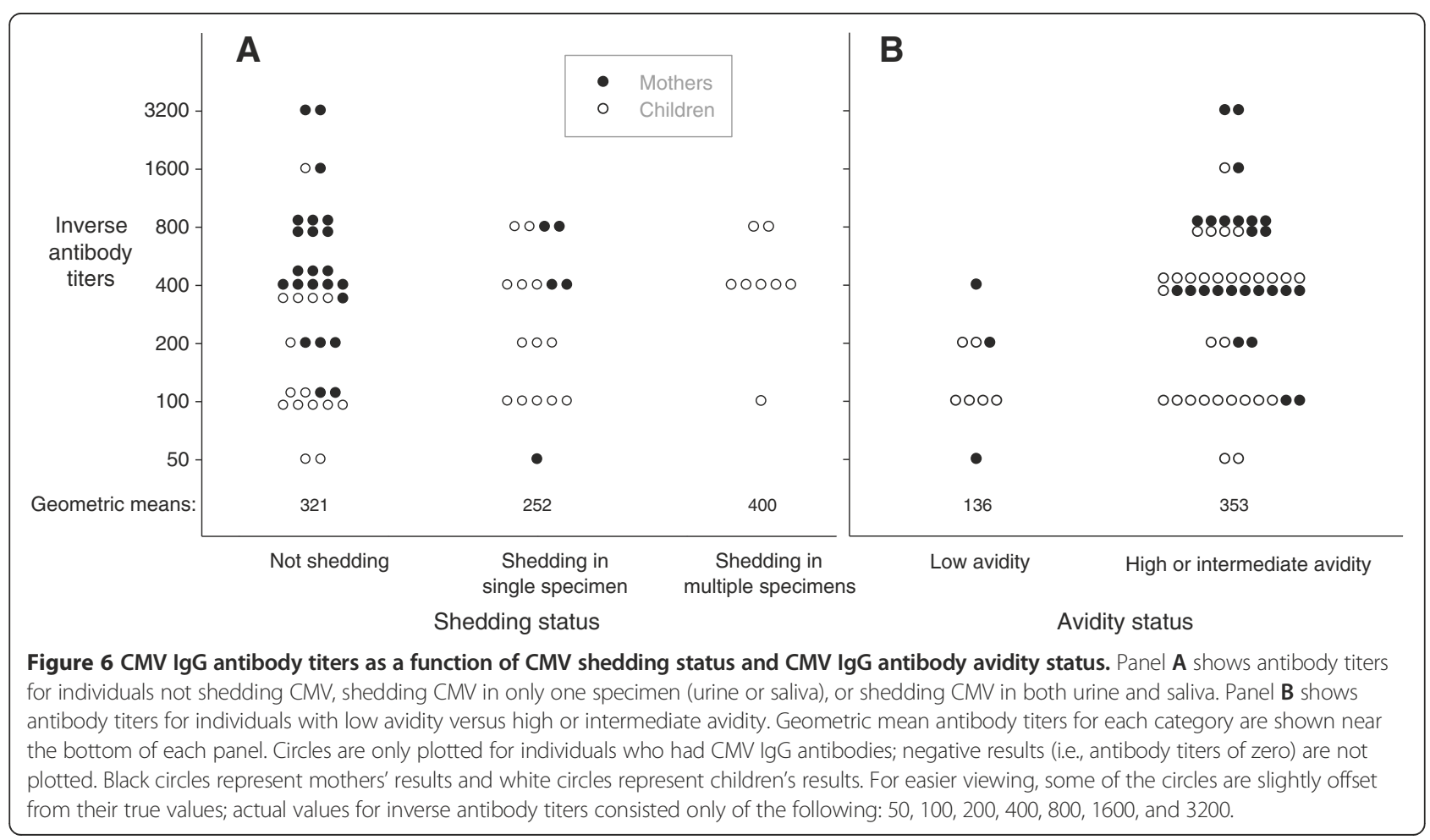


used viral culture, which might be partially responsible for our slightly different findings.

We also found that CMV viral loads were significantly higher in children's saliva and urine than in mothers' saliva, suggesting that children may be an especially important source of infection for pregnant women. Furthermore, the very highest viral loads (> one million copies $/ \mathrm{mL}$ ) were all in children's saliva, suggesting that exposure to saliva may pose an even greater risk for pregnant women than exposure to urine. We were only able to identify one previous study - from The Gambia - that compared viral loads in children and mothers [22]. In that study viral loads were similar in the saliva and urine of both groups. However, we might not expect similar results since the mothers and children in Atlanta may differ in important ways, such as nutritional status or co-morbidities, from the mothers and children in The Gambia [22]. Another study, among children at day care centers in Iowa, found slightly higher viral loads in saliva than in urine, but only four children were assessed [19].

CMV viral loads were higher among younger children, suggesting that they may be an especially important source of infection for pregnant women. This finding has not been shown previously, and might be explained in part by CMVinfected younger children being more likely to have a recent primary infection-since they have had fewer months to be exposed to reinfections-and viral primary infections tend to be associated with higher viral loads [52].

Among children, low CMV avidity was associated with younger age, higher viral loads, and lower antibody titers, which is consistent with the assumption that shedding in younger children is more likely to be associated with a primary CMV infection. In addition, the higher antibody titers among older children, and the higher antibody titers among mothers compared to children, are consistent with anti-CMV immune boosting through repeated antigenic exposures, whether due to reactivations or reinfections.

Our study had several limitations. First, our study children were identified through a convenience sample rather than a representative sample of the underlying population. They included an overrepresentation of both non-Hispanic Whites and Asians/Asian-Americans. Second, we screened only 161 children. Nevertheless, our sample was relatively large compared to previous studies that assessed CMV shedding and viral load in multiple body fluids of healthy young children. Third, we collected saliva and urine using different materials (i.e., swabs vs. filter paper), and so we could not directly compare shedding prevalences or median viral loads unless we excluded the saliva results that fell below the limit of PCR detection for urine. If we had been able to collect liquid urine we might have found a higher shedding prevalence in urine, but we may have also found that the difference between median viral loads would have become significantly higher for saliva (since some lower viral load results might have been added for urine). Fourth, we do not know whether any of the children in the study were infected congenitally because none was tested before three weeks of age. However, none of the children had a clinical diagnosis of congenital CMV and all were generally healthy. Fifth, we did not usually place the specimens in viral cultures but instead used PCR to quantify CMV DNA; thus, the presence of infectious virions was not demonstrated in most cases. This approach would be expected to overestimate the number of infectious particles in specimens. For a small number of specimens we also performed viral cultures and often found evidence for infectious virions (unpublished data). Nevertheless, as with other viruses that are typically detected using PCR, such as HIV or HSV-2, the high levels of viral DNA probably indicate the presence of infectious virions in most cases. Last, because this was a cross-sectional study, children were tested at only one time point. Because CMV shedding can be sporadic, some of the CMV-seropositive children who were not shedding at their study visit may have been shedding previously or subsequently. Thus, our estimate that $17 \%$ of children were shedders underestimates the prevalence of shedders over a longer time interval (Cannon et al., companion paper).

It is likely that some of the children originally acquired their CMV infections from their mothers via breast feeding. We did not ask questions about breast feeding and did not collect or test breast milk, so we cannot be sure whether the saliva of any of the children in the study was contaminated with CMV-infected breast milk. However, such contamination is unlikely because the study procedure mandated saliva collection no sooner than one hour after breastfeeding, and the young children's saliva viral loads were much higher than the peak viral loads typically found in breast milk [53,54].

Taken together, our findings can be used to inform behavioral prevention messages. To decrease transmission of CMV, the American Academy of Pediatrics (AAP) has advised hand hygiene when caring for children, particularly after changing diapers [55]. Similarly, the American College of Obstetricians and Gynecologists has advised women with young children to use safe-handling techniques after handling diapers or after exposure to respiratory secretions [56]. In addition to this advice, researchers who have conducted CMV behavioral interventions have also advised women to avoid kissing young children on the mouth, to refrain from sharing food, drink, and utensils, and to cleanse toys and other objects that may be exposed to children's body fluids $[1,12,14,57,58]$. Our findings suggest that although handwashing to minimize urine exposures is important (e.g., after diaper changes), behaviors that reduce saliva exposures may be even more important. Saliva appears to have higher CMV viral loads and is more likely to get into the 
environment through drooling, eating, pacifier use, etc. Urine, by contrast, is usually blocked by diapers. Furthermore, saliva has more opportunities to directly contact the eyes, nose and mouth of a pregnant woman (kissing, sharing food and drinks), whereas, urine contact is typically less direct (diaper-to-hand-to-eye). Because women may not recognize how frequently they come into contact with children's saliva, it may be important to emphasize behaviors that prevent saliva from directly contacting the mouth or other mucous membranes (e.g., kissing on the mouth or sharing food/drink and utensils).

\section{Conclusions}

Young CMV seropositive children, especially those less than one year-old may present high-risk CMV exposures to pregnant women, especially via saliva, though further research is needed to see if this finding can be generalized across racial or other demographic strata. Data on shedding among young children will be critical for developing and evaluating prevention messages and behavioral interventions in order to identify effective strategies to prevent CMV transmission.

\section{Competing interests}

The authors declare that they have no competing interests.

\section{Authors' contributions}

JDS helped design the study, coordinated and managed the data collection, participated in data analysis, and drafted the manuscript. KM collected data and participated in data analysis. MA processed specimens and carried out laboratory testing. RC collected data and participated in data analysis. DL helped design the study and participated in data collection. WH processed specimens and carried out laboratory testing. TML participated in data analysis. SCD helped design the study and supervised the laboratory testing. MJC conceived of the study, participated in its design, coordination, and data analysis, and helped draft the manuscript. All authors read the manuscript, revised it critically for important intellectual content, and approved the final manuscript.

\section{Acknowledgments}

We would like to thank DeKalb Pediatric Center in Decatur, GA, and Children's Medical Group and the Good Samaritan Health Center in Atlanta, GA for support in the recruitment process. Additionally, we would like to thank Cyndi Stover, Delaney Johnson, Karen Wu, and Phillip Dollard for significant contributions to recruitment and sample collection.

The findings and conclusions in this report are those of the authors and do not necessarily represent the official position of the Centers for Disease Control and Prevention.

\section{Author details}

${ }^{1}$ National Center on Birth Defects and Developmental Disabilities, Centers for Disease Control and Prevention, 1600 Clifton Rd NE, MS E-86, Atlanta, GA 30333, USA. ${ }^{2}$ National Center for Immunization and Respiratory Diseases, Centers for Disease Control and Prevention, Atlanta, GA, USA. ${ }^{3}$ Emory University, Atlanta, GA, USA.

Received: 12 May 2014 Accepted: 16 October 2014

Published online: 12 November 2014

\section{References}

1. Cannon MJ, Davis KF: Washing our hands of the congenital cytomegalovirus disease epidemic. BMC Public Health 2005, 5(1):70

2. Centers for Disease Control and Prevention: Knowledge and practices of obstetricians and gynecologists regarding cytomegalovirus infection during pregnancy-United States, 2007. MMWR Morb Mortal Wkly Rep 2008, 57(3):65-68.

3. Korver AMH, de Vries JJC, de Jong JW, Dekker FW, Vossen A, OudesluysMurphy AM: Awareness of congenital cytomegalovirus among doctors in the Netherlands. J Clin Virol 2009, 46:S11-S15.

4. Manicklal S, Emery VC, Lazzarotto T, Boppana SB, Gupta RK: The "silent" global burden of congenital cytomegalovirus. Clin Microbiol Rev 2013, 26(1):86-102.

5. Schleiss MR: Cytomegalovirus vaccine development. Human Cytomegalovirus 2008, 325:361-382

6. Stagno S, Remington JS, Klein JO: Cytomegalovirus. In Infectious Diseases of the Fetus and Newborn Infant. Edited by Remington JS, Klein JO. Philadelphia: WB Saunders Company; 2001:389-424.

7. Ross DS, Victor M, Sumartojo E, Cannon MJ: Women's knowledge of congenital cytomegalovirus: results from the 2005 HealthStyles survey. J Womens Health (Larchmt) 2008, 17(5):849-858.

8. Jeon J, Victor M, Adler S, Arwady A, Demmler G, Fowler K, Goldfarb J, Keyserling H, Massoudi M, Richards K, Staras SAS, Cannon MJ: Knowledge and awareness of congenital cytomegalovirus among women. Infect Dis Obstet Gynecol 2006, 2006:1-7.

9. Cordier AG, Guitton S, Vauloup-Fellous C, Grangeot-Keros L, Ayoubi JM, Benachi A, Picone O: Awareness of cytomegalovirus infection among pregnant women in France. J Clin Virol 2012, 53(4):332-337.

10. Lim SL, Tan WC, Tan LK: Awareness of and attitudes toward congenital cytomegalovirus infection among pregnant women in Singapore. Int J Gyn Obstet 2012, 117(3):268-272.

11. Mosher WD, Jones J, Abma JC: Intended and unintended birth in the United States: 1982-2010. Natl Health Stat Rep 2012, 55:1-28.

12. Adler SP, Finney JW, Manganello AM, Best AM: Prevention of child-tomother transmission of cytomegalovirus by changing behaviors: a randomized controlled trial. Pediatr Infect Dis J 1996, 15(3):240-246.

13. Picone O, Vauloup-Fellous C, Cordier AG, Du Chatelet IP, Senat MV, Frydman $R$, Grangeot-Keros L: A 2-year study on cytomegalovirus infection during pregnancy in a French hospital. BJOG 2009, 116(6):818-823.

14. Vauloup-Fellous C, Picone O, Cordier A-G, Parent-du-Chatelet I, Senat M-V, Frydman R, Grangeot-Keros L: Does hygiene counseling have an impact on the rate of CMV primary infection during pregnancy? Results of a 3-year prospective study in a French hospital. J Clin Virol 2009, 46S:S49-S53.

15. Hyde TB, Schmid DS, Cannon MJ: Cytomegalovirus seroconversion rates and risk factors: implications for congenital CMV. Rev Med Virol 2010, 20(5):311-326.

16. Griffiths PD: Strategies to prevent CMV infection in the neonate. Sem Neonatol 2002, 7(4):293-299.

17. Fowler KB, Pass RF: Risk factors for congenital cytomegalovirus infection in the offspring of young women: exposure to young children and recent onset of sexual activity. Pediatrics 2006, 118(2):e286-e292.

18. Strom J: A study of infections and illnesses in a day nursery based on inclusion-bearing cells in the urine and infectious agent in feces, urine and nasal secretion. Scand J Infect Dis 1979, 11:265-269.

19. Murph JR, Bale JF, Murray JC, Stinski MF, Perlman S: Cytomegalovirus transmission in a Midwest day care center: possible relationship to child care practices. J Pediatr 1986, 109:35-39.

20. Numazaki Y, Yano N, Morizuka T, Takai S, Ishida N: Primary infection with human cytomegalovirus: virus isolation from healthy infants and pregnant women. Am J Epidemiol 1970, 91(4):410-417.

21. Ahlfors $K$, Ivarsson SA, Johnsson T, Svensson I: Congenital and acquired cytomegalovirus infections. Virological and clinical studies on a Swedish infant population. Acta Paediatr Scand 1978, 67(3):321-328.

22. Bello C, Whittle H: Cytomegalovirus infection in Gambian mothers and their babies. J Clin Pathol 1991, 44(5):366-369.

23. Boppana SB, Fowler KB, Pass RF, Rivera LB, Bradford RD, Lakeman FD, Britt WJ: Congenital cytomegalovirus infection: association between virus burden in infancy and hearing loss. J Pediatr 2005, 146(6):817-823.

24. Cannon MJ, Hyde TB, Schmid DS: Review of cytomegalovirus shedding in bodily fluids and relevance to congenital cytomegalovirus infection. Rev Med Virol 2011, 21(4):240-255.

25. Collier AC, Handsfield HH, Ashley R, Roberts PL, DeRouen T, Meyers JD, Corey L: Cervical but not urinary excretion of cytomegalovirus is related to sexual activity and contraceptive practices in sexually active women. $J$ Infect Dis 1995, 171(1):33-38. 
26. Murph JR, Bale JF: The natural history of acquired cytomegalovirus infection among children in group day care. Am J Dis Child 1988, 142:843-846.

27. Natali A, Valcavi P, Medici MC, Dieci E, Montali S, Chezzi C: Cytomegalovirus infection in an Italian population: antibody prevalence, virus excretion and maternal transmission. New Microbiol 1997, 20(2):123-133.

28. Revello MG, Lilleri D, Zavattoni M, Furione M, Genini E, Comolli G, Gerna G: Lymphoproliferative response in primary human cytomegalovirus (HCMV) infection is delayed in HCMV transmitter mothers. J Infect Dis 2006, 193(2):269-276.

29. Spector SA, Schmidt K, Ticknor W, Grossman M: Cytomegaloviruria in older infants in intensive care nurseries. J Pediatr 1979, 95(3):444-446.

30. Stagno S, Reynolds D, Tsiantos A, Fuccillo DA, Smith R, Tiller M, Alford CA Jr: Cervical cytomegalovirus excretion in pregnant and nonpregnant women: suppression in early gestation. J Infect Dis 1975, 131(5):522-527.

31. Steininger C, Kundi M, Kletzmayr J, Aberle SW, Popow-Kraupp T: Antibody maturation and viremia after primary cytomegalovirus infection, in immunocompetent patients and kidney-transplant patients. J Infect Dis 2004, 190(11):1908-1912

32. Yan H, Koyano S, Inami Y, Yamamoto Y, Suzutani T, Mizuguchi M, Ushijima H, Kurane I, Inoue N: Genetic variations in the gB, UL144 and UL149 genes of human cytomegalovirus strains collected from congenitally and postnatally infected Japanese children. Arch Virol 2008, 153(4):667-674.

33. Kharrazi M, Hyde T, Young S, Amin MM, Cannon MJ, Dollard SC: Use of screening dried blood spots for estimation of prevalence, risk factors, and birth outcomes of congenital cytomegalovirus infection. J Pediatr 2010, 157(2):191-197.

34. Barbi M, Binda S, Primache V, Caroppo S, Dido P, Guidotti P, Corbetta C, Melotti D: Cytomegalovirus DNA detection in Guthrie cards: a powerful tool for diagnosing congenital infection. J Clin Virol 2000, 17(3):159-165.

35. Resident Population by Sex and Age: 1980 to 2010 (Table seven) [http://www.census.gov/prod/2011 pubs/12statab/pop.pdf]

36. Resident Population by Sex, Race, and Hispanic-Origin Status: 2000 to 2009 (Table six) [http://www.census.gov/prod/2011pubs/12statab/pop.pdf]

37. Educational Attainment by Selected Characteristics [http://www.census. gov/compendia/statab/2012/tables/12s0231.pdf]

38. Money Income of Households-Percent Distribution by Income Level, Race, and Hispanic Origin, in Constant (2009) Dollars: 1990 to 2009 (Table six hundred ninety) [http://www.census.gov/compendia/statab/ 2012/tables/12s0690.pdf]

39. Health Insurance Coverage Status by Selected Characteristics: 2008 and 2009 (Table one hundred fifty five) [http://www.census.gov/compendia/ statab/2012/tables/12s0156.pdf]

40. Who's Minding the Kids? Child Care Arrangements: Spring 2011 [http://www.census.gov/prod/2013pubs/p70-135.pdf]

41. Bate SL, Dollard SC, Cannon MJ: Cytomegalovirus seroprevalence in the United States: the national health and nutrition examination surveys, 1988-2004. Clin Infect Dis 2010, 50(11):1439-1447.

42. Adler SP: Molecular epidemiology of cytomegalovirus: viral transmission among children attending a day care center, their parents, and caretakers. J Pediatr 1988, 112(3):366-372.

43. Hutto C, Ricks R, Garvie M, Pass RF: Epidemiology of cytomegalovirus infections in young children: day care vs. home care. Pediatr Infect Dis 1985, 4(2):149-152.

44. Strangert $K$, Carlstrom G, Jeanson S, Nord C-E: Infections in pre-schoo children in group day care. Acta Pediatr Scand 1976, 65:455-463.

45. Pass RF, Hutto SC, Reynolds DW, Polhill RB: Increased frequency of cytomegalovirus infection in children in group day care. Pediatrics 1984, 74(1):121-126.

46. Leinikki P, Heinonen K, Pettay O: Incidence of cytomegalovirus infections in early childhood. Scand J Infect Dis 1972, 4(1):1-5.

47. Li F, Hanshaw JB: Cytomegalovirus infection among migrant children. AmJ Epidemiol 1967, 86(1):137-141.

48. Pass RF, Stagno S, Dworsky ME, Smith RJ, Alford CA: Excretion of cytomegalovirus in mothers: observations after delivery of congenitally infected and normal infants. J Infect Dis 1982, 146(1):1-6.

49. Revello MG, Campanini G, Piralla A, Furione M, Percivalle E, Zavattoni M, Gerna G: Molecular epidemiology of primary human cytomegalovirus infection in pregnant women and their families. J Med Virol 2008, 80(8):1415-1425.
50. Zanghellini F, Boppana SB, Emery VC, Griffiths PD, Pass RF: Asymptomatic primary cytomegalovirus infection: virologic and immunologic features. J Infect Dis 1999, 180(3):702-707.

51. Kaye S, Miles D, Antoine P, Burny W, Ojuola B, Kaye P, Rowland-Jones S, Whittle $H$, van der Sande M, Marchant A: Virological and immunological correlates of mother-to-child transmission of cytomegalovirus in The Gambia. J Infect Dis 2008, 197(9):1307-1314.

52. Virgin S: Pathogenesis of viral infection. In Fields Virology. Edited by Knipe DM, Howley PM. Philadelphia, PA: Lippincott Williams \& Wilkins; 2007:327-388.

53. Chiavarini M, Bragetti $P$, Sensini A, Cenci E, Castronari R, Rossi MJ, Fantauzzi A, Minelli L: Breastfeeding and transmission of cytomegalovirus to preterm infants. Case report and kinetic of CMV-DNA in breast milk. Ital J Pediatr 2011, 37:6.

54. Ehlinger EP, Webster EM, Kang HH, Cangialose A, Simmons AC, Barbas KH, Burchett SK, Gregory ML, Puopolo KP, Permar SR: Maternal cytomegalovirusspecific immune responses and symptomatic postnatal cytomegalovirus transmission in very low-birth-weight preterm infants.

J Infect Dis 2011, 204(11):1672-1682.

55. American Academy of Pediatrics: Red Book: 2012 Report of the Committee on Infectious Diseases. 29th edition. Elk Grove Village, IL: American Academy of Pediatrics; 2012

56. American College of Obstetricians and Gynecologists: Perinatal Viral and Parasitic Infections. ACOG Practice Bulletin 20. Washington, DC: ACOG; 2000.

57. Nigro G, Adler SP: Cytomegalovirus infections during pregnancy. Curr Opin Obstet Gynecol 2011, 23(2):123-128.

58. Demmler-Harrison GJ: Congenital cytomegalovirus: public health action towards awareness, prevention, and treatment. J Clin Virol 2009, 46:S1-S5.

doi:10.1186/s12879-014-0568-2

Cite this article as: Stowell et al:: Cross-sectional study of cytomegalovirus shedding and immunological markers among seropositive children and their mothers. BMC Infectious Diseases 2014 14:568.

\section{Submit your next manuscript to BioMed Central and take full advantage of:}

- Convenient online submission

- Thorough peer review

- No space constraints or color figure charges

- Immediate publication on acceptance

- Inclusion in PubMed, CAS, Scopus and Google Scholar

- Research which is freely available for redistribution 